\title{
Forage type influences milk yield and ruminal responses to wheat adaptation in late-lactation dairy cows
}

\author{
V. M. Russo, $\left.{ }^{*}\right\rceil \ddagger^{1}$ B. J. Leury, † E. Kennedy, $\ddagger$ M. C. Hannah, ${ }^{*}$ M. J. Auldist, ${ }^{*}$ and W. J. Wales* \\ ${ }^{*}$ Agriculture Victoria Research, 1301 Hazeldean Road, Ellinbank, Victoria 3821, Australia \\ †Faculty of Veterinary and Agricultural Sciences, The University of Melbourne, Parkville, Victoria 3010, Australia \\ $\ddagger$ Teagasc, Animal and Grassland Research and Innovation Centre, Moorepark, Fermoy, Co. Cork, P61 C996 Ireland
}

\section{ABSTRACT}

The effects of different wheat adaptation strategies on ruminal fluid $\mathrm{pH}$, dry matter intake (DMI) and energy-corrected milk (ECM) were measured in 28 latelactation dairy cows. Cows were fed either perennial ryegrass (PRG) hay or alfalfa hay and had no previous wheat adaptation. Wheat was gradually substituted for forage in 3 even increments, over 6 or $11 \mathrm{~d}$, until wheat made up $40 \%$ of DMI $(\sim 8 \mathrm{~kg}$ of dry matter/cow per day). We found no differences in DMI between adaptation strategies (6 or $11 \mathrm{~d}$ ) within forage type; however, cows fed alfalfa hay consumed more overall and produced more ECM. The rate of ruminal $\mathrm{pH}$ decline after feeding, as well as the decrease in mean, minimum, and maximum ruminal $\mathrm{pH}$ with every additional kilogram of wheat was greater for cows fed alfalfa hay. Cows fed alfalfa hay and on the 6-d adaptation strategy had the lowest mean and minimum ruminal fluid $\mathrm{pH}$ on 3 consecutive days and were the only treatment group to record $\mathrm{pH}$ values below 6.0. Despite ruminal $\mathrm{pH}$ declining to levels typically considered low, no other measured parameters indicated compromised fermentation or acidosis. Rather, cows fed alfalfa hay and adapted to wheat over $6 \mathrm{~d}$ had greater ECM yields than cows on the 11-d strategy. This was due to the 6-d adaptation strategy increasing the metabolizable energy intake in a shorter period than the 11-d strategy, as substituting wheat for alfalfa hay caused a substantial increase in the metabolizable energy concentration of the diet. We found no difference in ECM between adaptation strategies when PRG hay was fed, as there was no difference in metabolizable energy intake. The higher metabolizable energy concentration and lower intake of the PRG hay meant the increase in metabolizable energy intake with the substitution of wheat was less pronounced

Received February 2, 2018.

Accepted June 29, 2018.

${ }^{1}$ Corresponding author: victoria.russo@ecodev.vic.gov.au for cows consuming PRG hay compared with alfalfa hay. Neither forage type nor adaptation strategy affected time spent ruminating. The higher intakes likely contributed to the lower ruminal $\mathrm{pH}$ values from the alfalfa hay treatments. However, both forages allowed the rumen contents to resist the large declines in ruminal $\mathrm{pH}$ typically seen during rapid grain adaptation. Depending on the choice of base forage, rapid grain introduction may not result in poor adaptation. In situations where high-energy grains are substituted for a low-energy, high-fiber basal forage, rapid introduction could prove beneficial over gradual strategies.

Key words: ruminal $\mathrm{pH}$, buffering capacity, alfalfa hay, perennial ryegrass hay

\section{INTRODUCTION}

In dairying industries where pasture makes up the majority of the cows' diet, such as those in Victoria, Australia, energy needs are often met through supplementation with cereal grains or pelleted concentrates (Bargo et al., 2003). Due to large seasonal variability in the nutrient supply from pasture (Roche et al., 2009) and changing energy demands throughout lactation (NRC, 2001), the amount of concentrates provided may be altered accordingly. This could mean increasing concentrate feeding rates several times throughout a lactation, which is known as stepped flat-rate feeding (Leaver, 1988). The introduction of increasing amounts of rapidly digestible concentrates and their subsequent fermentation results in the rapid production of VFA, and possibly lactate, causing declines in ruminal fluid $\mathrm{pH}$ (Wales and Doyle, 2003). Low ruminal fluid $\mathrm{pH}$, in turn, can lead to compromised fiber digestion, variable feed intake, and metabolic diseases such as acidosis (Mould et al., 1983; Owens et al., 1998; Krause and Oetzel, 2006).

Despite the widespread use of concentrates in Australian dairy systems, forages still make up the majority of the diet and play a pivotal role in optimizing rumen function. The contribution of forages to maintaining 
a stable ruminal $\mathrm{pH}$ derive largely from their effects on fermentation and rumination (Allen et al., 2006). Due to a relatively low NDF fraction, legumes are more rapidly digested than grasses, allowing for greater DMI and a faster rate of acid production (Van Soest, 1965; Smith et al., 1972). However, legumes have a high intrinsic buffering capacity relative to other forages (Greenhill, 1964; Wohlt et al., 1987), thought to be a consequence of a higher cation exchange capacity and higher protein concentration (McBurney et al., 1983). An ability to buffer the ruminal contents when large amounts of rapidly fermentable starch are consumed is critical in high-concentrate systems. Grasses, which are fermented more slowly but have a lower intrinsic buffering capacity (McBurney et al., 1983), are likely to have less ability to resist ruminal $\mathrm{pH}$ changes. As well as influencing DMI and digestion, the fiber concentration of forages also has a role in buffering the rumen during fermentation of concentrates by positively influencing rumination time, which determines saliva production, the main source of buffers within the rumen (Allen, 1997; Allen et al., 2006; Krause and Oetzel, 2006).

Part of a successful adaptation strategy is maintaining ruminal $\mathrm{pH}$ within an optimum range, which for forage-concentrate diets is suggested to be $\mathrm{pH} 6.0$ to 6.3 (Hutjens and Overton, 1996; Pitt et al., 1996). Strategies such as combining concentrates with forages as a mixed ration or offering a greater number of smaller meals positively influences ruminal pH (Kaufmann, 1976; Auldist et al., 2013). However, the majority of dairy farmers in Australia do not feed mixed rations and offer relatively large amounts of concentrates $(>1.0$ $\mathrm{t} /$ cow per year) during milking, with the most common being barley grain and wheat grain (Dairy Australia, 2015). This type of feeding system creates the challenge of a twice-daily rapid increase in fermentation acids within the rumen. The guidelines around introducing large amounts of cereal grains to forage-fed dairy cows are vague, with recommended introduction periods ranging from 10 to $21 \mathrm{~d}$ and the quantity being gradually increased every 2 to $3 \mathrm{~d}$ (Warner, 1962; Tremere et al., 1968; Kellaway and Harrington, 2004). It is desirable to shorten this adaptation period in order to simplify management strategies and increase the ME intake of the herd to maximize milk production. However, making such abrupt dietary changes heightens the risk of acidosis and animals refusing feed, particularly when the concentrate offered is ground wheat (Tremere et al., 1968) due to high rumen fermentability (GonzalezRivas et al., 2016).

The objective of our experiment was to compare 2 strategies to introduce large amounts $(\sim 8 \mathrm{~kg}$ of $\mathrm{DM} /$ cow per day) of crushed wheat grain into the diet of late-lactation dairy cows previously fed only perennial ryegrass (PRG) hay or alfalfa hay and determine the effects on ruminal fluid $\mathrm{pH}$, milk yield (MY), and DMI. The decision to use conserved forages was based on situations where fresh grazed forages are limiting in pasture-based systems. The hypotheses tested were (1) that feeding PRG hay in combination with wheat would result in a lower mean ruminal fluid $\mathrm{pH}$ than feeding alfalfa hay and wheat, and (2) that the mean ruminal fluid $\mathrm{pH}$ of cows introduced wheat in $6 \mathrm{~d}$ would not differ from that of cows introduced wheat in $11 \mathrm{~d}$, irrespective of forage type.

\section{MATERIALS AND METHODS}

\section{Experimental Design and Dietary Treatments}

The experiment was conducted at the Department of Economic Development, Jobs, Transport and Resources, Ellinbank Centre, Victoria, Australia (38 $14^{\prime} \mathrm{S}$, $\left.145^{\circ} 56^{\prime} \mathrm{E}\right)$. All procedures were conducted in accordance with the Australian Code of Practice for the Care and Use of Animals for Scientific Purposes (National Health and Medical Research Council, 2013). Approval to proceed was obtained from the Department of Economic Development, Jobs, Transport and Resources Agricultural Research and Extension Animal Ethics Committee.

Twenty-eight rumen-fistulated Holstein-Friesian dairy cows in lactation 2 to 9 were used. All cows were seasonally calving and were in late lactation, having calved between July and October 2015 (235 \pm 27.4 DIM; mean \pm SD). Milking occurred twice daily at 0600 and $1500 \mathrm{~h}$. The experiment was conducted over a 35-d period, composed of a 7-d covariate period, a 14-d forage adaptation period, and a 14-d measurement period that included a 6- or 11-d introduction of wheat. Cows were moved to individual pens for feeding and were kept in a bare paddock between feeding bouts with no available feed but water available ad libitum. During the covariate period, cows were individually offered a 50:50 mix of PRG hay and alfalfa hay ad libitum and DMI were measured over the final $3 \mathrm{~d}$. Following this, 4 treatments were each allocated to 7 cows, balancing treatment groups for DMI, BW, age, DIM, and current MY using the method of Harville (1974) implemented in the software GenStat for Windows as the procedure COVDESIGN (GenStat 18th ed.; VSN International Ltd., Hemel Hempstead, UK). Each treatment substituted wheat for forage in 3 even increments (each $13.3 \%$ of total DM) until wheat comprised $40 \%$ of DM offered. The 4 treatments were (1) alfalfa hay with a 6-d wheat adaptation strategy (ALF6), (2) alfalfa hay 
Table 1. Wheat (\% of DM) offered over the experimental period for each of the treatment diets

\begin{tabular}{|c|c|c|c|c|c|c|c|c|c|c|c|c|c|c|}
\hline Item $^{1}$ & \multicolumn{14}{|c|}{ Treatment day } \\
\hline ALF6 & 0 & 13 & 13 & 13 & 27 & 27 & 40 & 40 & 40 & 40 & 40 & 40 & 40 & 40 \\
\hline PRG6 & 0 & 13 & 13 & 13 & 27 & 27 & 40 & 40 & 40 & 40 & 40 & 40 & 40 & 40 \\
\hline PRG11 & 0 & 13 & 13 & 13 & 13 & 13 & 27 & 27 & 27 & 27 & 27 & 40 & 40 & 40 \\
\hline
\end{tabular}

${ }^{1}$ Treatments: ALF6 = cows fed alfalfa hay with wheat introduced over 6 d; ALF11 = cows fed alfalfa hay with wheat introduced over 11 d; PRG6 $=$ cows fed PRG hay with wheat introduced over $6 \mathrm{~d}$; PRG11 = cows fed PRG hay with wheat introduced over $11 \mathrm{~d}$.

with an 11-d wheat adaptation strategy (ALF11), (3) PRG hay with a 6-d wheat adaptation (PRG6), and (4) PRG hay with an 11-d wheat adaptation strategy (PRG11).

On the first day of the forage adaptation period, the diet of individual cows was changed to only include their allocated forage. They remained on this forageonly diet for the entirety of the adaptation period, during which individual DMI were measured. During the measurement period, each cow was fed at a rate equivalent to $90 \%$ of her DMI during the adaptation period to minimize refusals and the opportunity for cows to select. Wheat introduction began on the second day of the measurement period. A schedule of the dietary proportion of wheat offered each day to individual cows within each treatment is presented in Table 1. Following each milking, cows were moved to individual stalls and given half their ration in the morning and half in the afternoon. Wheat was offered first, and after 30 min any remaining wheat was removed before forage was offered. All cows were given $3.5 \mathrm{~h}$ to consume their forage, and water was offered twice during this time.

\section{Intake and Nutritive Characteristics}

All feed offered and refused was weighed and a representative sample was collected per cow at each feeding. Part of each sample was then dried at $100^{\circ} \mathrm{C}$ for $24 \mathrm{~h}$ to determine DM concentration, which facilitated the calculation of individual DMI. The remainder of the samples were then bulked by feed type or, in the case of refusals, by individual cow and stored at $4^{\circ} \mathrm{C}$. At the completion of the experiment, bulked samples were thoroughly mixed and representative subsamples were freeze-dried and ground to pass through a 1-mm screen. The samples were then analyzed for $\mathrm{CP}$, amylase-treated NDF (aNDF), ADF, lignin, NFC, starch, crude fat $(\mathbf{C F})$, ash, TDN, and minerals by wet chemistry in a commercial laboratory (Dairy One Forage Laboratory, Ithaca, NY). Concentrations of estimated ME were calculated using the formula (NRC, 2001)

$$
\begin{gathered}
\text { Estimated ME }(\mathrm{MJ} / \mathrm{kg} \text { of } \mathrm{DM})= \\
\{[1.01 \times(0.04409 \times \mathrm{TDN} \%)]-0.45\} \times 4.184 .
\end{gathered}
$$

Particle size distribution of the wheat grain was determined following the method described by Moate et al. (2017).

\section{Eating Behavior}

On $\mathrm{d} 1$ and 14 of the measurement period, the eating behavior of all cows was monitored over a 24-h period. On d 1, all cows were on a forage-only diet, whereas on d 14 all cows were offered the maximum amount of wheat at $40 \%$ of total diet DM. During the $24-\mathrm{h}$ periods, cows were observed every $10 \mathrm{~min}$. Their activity was recorded as either eating, ruminating, or not chewing. It was assumed that each observation represented the activity for the previous $10 \mathrm{~min}$ (Gary et al., 1970).

\section{Milk Yield and Composition}

Milk yields were recorded using a milk metering system (MM25; DeLaval International, Tumba, Sweden), which is calibrated every 2 wk and has an accuracy of $\pm 3 \%$. A proportionate subsample was collected at each milking from each individual cow using in-line milk samplers. Individual samples were analyzed for protein, fat, and lactose concentrations using an infrared milk analyzer (Model 2000; Bentley Instruments, Chaska, $\mathrm{MN})$. Energy-corrected milk yield was calculated using the formula (Tyrrell and Reid, 1965)

$$
\begin{gathered}
\mathrm{ECM}(\mathrm{kg} / \text { cow per day })=\mathrm{MY}(\mathrm{kg} / \text { cow per day }) \\
\times[376 \times \text { fat }(\%)+209 \times \operatorname{protein}(\%)+948] / 3,138
\end{gathered}
$$

\section{Ruminal Fluid pH, VFA, Ammonia, and Lactate}

At the commencement of the covariate period, loggers for measuring ruminal pH (KB5; Kahne Ltd., Auckland, New Zealand) were calibrated and inserted 
per fistula into the rumen of each cow. The capsules remained in the cows until the end of the measurement period. A 750-g weight was attached to each capsule to ensure it remained on the floor of the rumen. An average ruminal $\mathrm{pH}$ was logged for every 5 -min interval, and data were automatically stored in the devices. Capsules were removed once a week for $8 \mathrm{~h}$ to validate the $\mathrm{pH}$ readings, and a linear interpolation was used on each individual bolus data to correct for any drift in readings between calibration and validation, assuming a uniform rate of drift. Following the validation, all data were downloaded and boluses were recalibrated before reinsertion.

Samples of ruminal fluid were collected on measurement $\mathrm{d} 1,4,9$, and 14 . On these days, immediately before the morning feeding, cows were individually moved to a squeeze chute and the first sample was collected (prefeed). A second sample was collected 4 $\mathrm{h}$ after feeding had commenced (postfeed) while cows remained in their individual stalls and were restrained using a locking head yoke. Samples were collected per fistula using a $100-\mathrm{mL}$ plastic syringe connected to a copper pipe directly inserted into the rumen. Fluid was collected from 4 sites within the rumen (in the fiber mat, below the fiber mat, anterior to the fiber mat, and midway down the posterior end of the fiber mat) and mixed thoroughly. A 50-mL subsample was immediately poured off and centrifuged $\left(4^{\circ} \mathrm{C}, 4,000 \times g, 10-\mathrm{min}\right)$ and the $\mathrm{pH}$ of the remainder was determined using a benchtop pH meter (Orion star A211; Thermo Fisher Scientific, Scoresby, Victoria, Australia). A 0.5-mL aliquot of supernatant was then transferred to a tube containing $4.5 \mathrm{~mL}$ of dilute acid ( $2 \%$ formic acid) for later analysis of ammonia. An additional 5-mL aliquot was stored for analyses of VFA and lactate. Both subsamples were kept at $-20^{\circ} \mathrm{C}$ until analyzed. Volatile fatty acid concentrations were determined by capillary GC (Agilent 6890 GC; Agilent Technologies, Santa Clara, $\mathrm{CA}$ ) with a flame ionization detector, autosampler and auto-injector, and a wide-bore capillary column [BP21 column, $12 \mathrm{~m} \times 0.53 \mathrm{~mm}$ internal diameter (i.d.) and $0.5 \mu \mathrm{m}$ film thickness; SGE International, Ringwood, Victoria, Australia] with retention gap kit (including a $2 \mathrm{~m} \times 0.53 \mathrm{~mm}$ i.d. guard column). Analyses were conducted following the methodology described by Packer et al. (2011) with 4-methyl-valeric acid (184 $\mu \mathrm{L} / \mathrm{L})$ used as the internal standard. Lactate analyses were conducted with a microplate reader (AMR-100; Hangzhou Allsheng Instruments, Hangzhou, China) using a D-/L-lactate kit (K-DLATE; Megazyme, Bray, Ireland). Ammonia-N concentrations were determined by flow-injection (Lachat Quik-Chem 8000; Lachat Instruments, Milwaukee, WI) according to an alkaline phenol-based method (method 12-107-06-1-A; Lachat Instruments) and analyzed against standard ammonia solutions (QuikChem Systems, 2008).

\section{Titratable Acidity and Buffering Capacity}

The methodology of Playne and McDonald (1966) was used to perform an acid titration on each of the forages. A subsample of each of the forage samples collected for nutritive analyses was stored at $-18^{\circ} \mathrm{C}$. After the experiment, each forage sample was divided into 3 replicates, each weighing approximately $10 \mathrm{~g}$ (exact weights were recorded). Each replicate was mixed with $250 \mathrm{~mL}$ of deionized water and blended for $20 \mathrm{~s}$ (NutriBullet 1000; NutriBullet, Brisbane, Queensland, Australia). The solution was then stirred continuously and, after $5 \mathrm{~min}$, a $\mathrm{pH}$ value was obtained (Orion star A211; Thermo Fisher Scientific) and recorded as the initial $\mathrm{pH}$. An automatic potentiometric titrator (809 Titrando; Metrohm AG, Herisau, Switzerland) was used to perform an acid titration on each sample. Hydrochloric acid $(0.1 \mathrm{~N})$ was added gradually to reduce the $\mathrm{pH}$ to 5.50. The method of Jasaitis et al. (1987) was applied to describe the results. The volume of acid added was multiplied by the normality to calculate the titratable acidity. The known DM percentage was used to calculate grams of DM of sample, and the titratable acidity was described as the milliequivalents of $\mathrm{HCl} \mathrm{re-}$ quired to decrease the $\mathrm{pH}$ of $100 \mathrm{~g}$ of $\mathrm{DM}$ of sample to 5.50. All sample titrations were corrected for a $250-\mathrm{mL}$ water blank. Acid buffering capacity was calculated by dividing the titratable acidity by the total change in $\mathrm{pH}$ units (i.e., initial pH minus 5.50); therefore, acid buffering capacity describes the amount of acid required to generate a unit change in $\mathrm{pH}$ of $100 \mathrm{~g}$ of $\mathrm{DM}$ of the sample.

\section{Statistical Analyses}

All data were analyzed using Genstat for Windows (Genstat 18th ed.; VSN International Ltd.). Milk production data, including the covariate period, forage adaptation period, and the measurement period, were analyzed using a mixed effects model comprising 1 fixed effect and crossed random effects. The fixed effect consisting of a single factor with 1 level for forage (PRG and alfalfa mix) in the covariate period, 2 levels for forage in the adaptation period (PRG or alfalfa), and a level for each combination of forage by adaptation strategy by day in the measurement period. The random effects of the mixed model were cow crossed with day. Other models for repeated measures, such as autocorrelation, in the random effects were compared 
by Akaike information criterion, but not required. Statistical tests for the hypothesized effects within the measurement period for forage (alfalfa hay vs. PRG hay), adaptation strategy (11 vs. $6 \mathrm{~d}$ ), and for their interaction, were obtained as $t$-tests by defining contrasts between relevant means. The main effect treatment means, for example, were obtained by linear combinations averaging over the relevant diet by adaptation strategy by day means predicted by the fitted mixed model. Standard errors, used in the $t$-test denominators of the contrasts, were computed correspondingly from the variance-covariance matrix of the predicted means. Behavior data from d 1 and 14 were analyzed using an ANOVA with a blocking structure of cow split for day and factorial treatment structure of forage type by adaptation strategy by wheat percentage. Nonsignificant interaction terms were dropped from the model to simplify presentation. The composition of ruminal fluid sampled on d 1, 4, 9, and 14 were subjected to mixed model analysis. Random effects for cow split for day split for time were used along with factorial treatment structure of adaptation strategy by forage-type by time by percentage of wheat in the diet. Ruminal fluid $\mathrm{pH}$ pre- and postfeed for each cow on d 1, 4, 9, and 14 were analyzed using a similar mixed model with random effects for cow split for day split for sampling time (pre- or postfeed) and factorial fixed effects for forage by adaptation strategy by wheat proportion by sampling time. Adaptation strategy was not significant and was dropped from the model to simplify presentation. Rates of decline in $\mathrm{pH}$ over the $4 \mathrm{~h}$ following the morning feeding were calculated for each cow on $\mathrm{d} 1$, 4, 9, and 14. These were subjected to ANOVA with blocking structure of cow split for day and factorial treatment structure of adaptation strategy by forage by day. The analysis was also conducted using a factor for the percentage of wheat in the diet to replace the factor for day in the treatment structure. This was required analysis by ReML software to allow for imbalance on d 9 when the 6- and 11-d adaptation strategies had differing percentages of wheat in the diet (40 and $27 \%$, respectively). Nonsignificant interaction terms were dropped from the model to simplify presentation. Ruminal fluid $\mathrm{pH}$ data from several boluses were unavailable. The number of cows having bolus data available were 6, 5, 5, and 7 for ALF6, ALF11, PRG6, and PRG11, respectively. Bolus data were summarized daily for each cow as daily mean, minimum, and maximum, and data were subjected to mixed model analysis with a fixed effect for the data in the covariate period and factorial fixed effects for forage-diet by adaptation strategy by day. The random effects were specified as an autoregressive order 1 process for day within cow. An ANOVA was performed on change in $\mathrm{pH}$ per kilogram of wheat added to the diet between the day before applying a wheat increment and the day on which the increment was applied (or the following day in the case of $\mathrm{d} 7$ when no bolus data were recorded). These $\mathrm{pH}$ change rate data were calculated and averaged for each cow before analysis. The ANOVA had factorial treatment structure, forage diet by strategy, and cow as the unit. Three variables were analyzed: change in daily mean, maximum, and minimum $\mathrm{pH}$ per change in kilograms of DMI wheat. Days (i.e., measurement days) were defined from 0800 to $0759 \mathrm{~h}$. The amount of milliequivalents of $\mathrm{HCl}$ per $100 \mathrm{~g}$ of $\mathrm{DM}$ added to reach a $\mathrm{pH}$ of 5.50 was recorded from the acid titrations for each of the 3 replicates of the 2 forage samples; these data were analyzed by ANOVA.

\section{RESULTS}

\section{Nutritive and Dry Matter Intake}

Concentrations of $\mathrm{CP}$, aNDF, ADF, lignin, NFC, starch, CF, ash, TDN, estimated ME, DCAD, and cation fraction of the feeds offered are presented in Table 2. The particle size distribution of the crushed wheat grain as a percentage of DM retained on sieve was $61 \%$ large ( $\geq 2 \mathrm{~mm}$ ), $29 \%$ medium (between 1 and $2 \mathrm{~mm}$ ), and $10 \%$ fine $(<1 \mathrm{~mm})$. The mean $( \pm \mathrm{SD})$ particle size distribution of the hays as a percentage of DM retained on sieve was $77 \%( \pm 2.2)$ large $(\geq 2 \mathrm{~mm}), 11 \%( \pm 3.1)$ medium (between 1 and $2 \mathrm{~mm}$ ), and $12 \%$ ( \pm 4.3 ) fine $(<1 \mathrm{~mm})$. Mean DMI of forage and wheat for each of the treatments are shown in Figure 1. The mean DMI for cows fed alfalfa hay and PRG hay during the measurement period was 18.6 and $15.7 \mathrm{~kg} \mathrm{DM} / \mathrm{cow}$ per day, respectively. Once the maximum proportion of wheat $(40 \% \mathrm{DM})$ had been reached, daily DMI $(\mathrm{kg} /$ cow) of wheat were $7.4 \pm 0.07,7.5 \pm 0.13,6.2 \pm 0.07$, and $6.3 \pm 0.12$ and of forage were $11.3 \pm 0.13,11.3 \pm$ $0.22,9.3 \pm 0.13$, and $9.4 \pm 0.21$ (mean \pm SEM) for ALF6, ALF11, PRG6, and PRG11, respectively. The mean daily estimated ME intake for each of the treatment groups are presented in Figure 2. The estimated ME intake increased over the duration of the experiment $(P<0.001)$ and cows fed alfalfa hay consumed more estimated ME overall than cows fed PRG hay $(P<0.001)$. Whereas the total amount of estimated ME consumed during the experiment was not different between adaptation strategies, on d 5 through 10 ALF6 cows were consuming an average of $14.2 \mathrm{MJ} / \mathrm{d}$ more than cows in the ALF11 treatment group $(P<0.05)$. 
Table 2. Nutritive characteristics of feed offered during the experimental period ${ }^{1}$

\begin{tabular}{lcccccccccrrr}
\hline Item & CP & aNDF & ADF & Lignin & NFC & Starch & CF $^{3}$ & Ash & TDN $^{*}$ ME $^{4}$ & DCAD $^{5}$ & Cation $^{2}$ \\
\hline Alfalfa hay & 18.5 & 46.0 & 35.8 & 7.3 & 20.3 & 0.7 & 2.9 & 12.4 & 56 & 8.6 & 62 \\
PRG hay & 14.9 & 57.3 & 35.9 & 4.3 & 17.5 & 0.3 & 2.1 & 8.4 & 61 & 9.4 & 42 & 2.4 \\
Wheat grain & 14.7 & 10.8 & 4.1 & 0.9 & 70.5 & 63.9 & 2.2 & 1.9 & 86 & 14 & -1 & 0.5 \\
\hline
\end{tabular}

${ }^{1}$ All values are $\%$ of DM unless otherwise indicated.

${ }^{2}$ Amylase-treated neutral detergent fiber (aNDF), analyzed by using heat-stable amylase and sodium sulfite.

${ }^{3}$ Crude fat (ether extract).

${ }^{4}$ Estimated (MJ/kg of DM).

${ }^{5}$ Milliequivalents/100 g of DM, DCAD $=[(\% \mathrm{Na} / 0.023)+(\% \mathrm{~K} / 0.039)]-[(\% \mathrm{~S} / 0.016)+(\% \mathrm{Cl} / 0.0355)]$.

\section{Ruminal Fluid pH, VFA, Ammonia, and Lactate}

Pre and postfeed ruminal fluid $\mathrm{pH}$, concentrations of total VFA, proportions of individual VFA, ammonia concentrations, and lactate concentrations are presented in Table 3. The average prefeed ruminal fluid $\mathrm{pH}$ was not different for cows being offered either of the forages $(\mathrm{pH} 6.68, P=0.508)$. The difference oc- curred postfeed $(P<0.001)$, as the ruminal fluid $\mathrm{pH}$ of cows fed PRG hay declined to 6.39, whereas the $\mathrm{pH}$ of those fed alfalfa hay declined to 6.10. Ruminal fluid $\mathrm{pH}$ consistently declined between the prefeed and the postfeed sample $(P<0.001)$. An average of the change per hour for the 2 forage types is presented in Figure 3 . The adaptation strategy had no effect $(P=0.563)$, thus the results have been averaged across both the a)

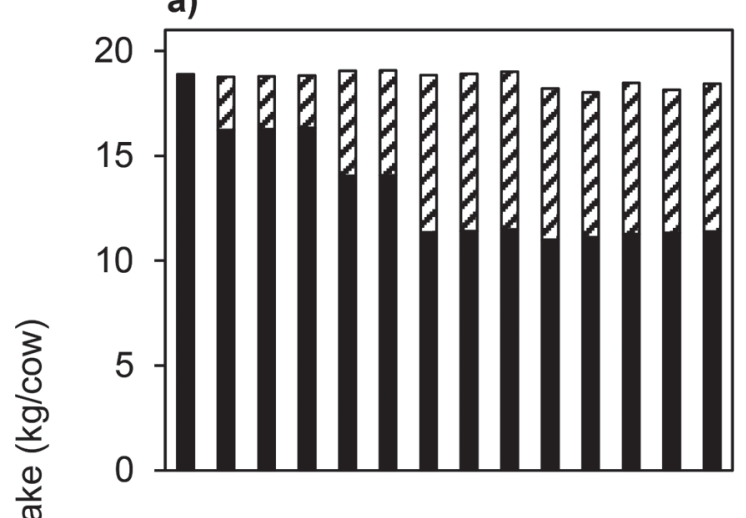

c)

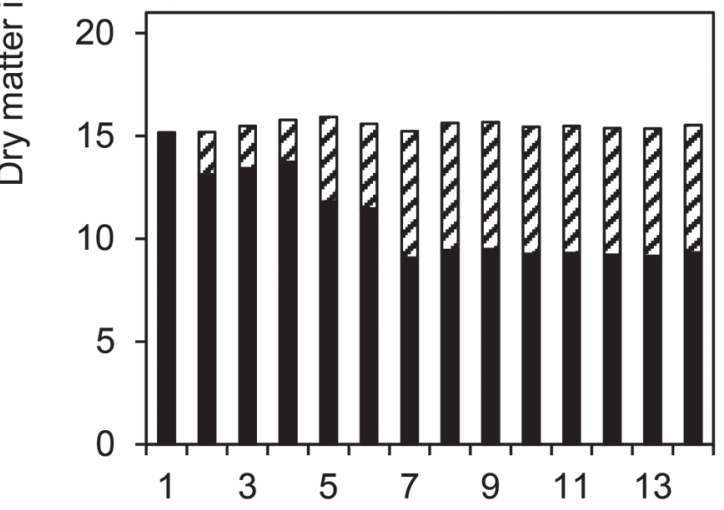

b)

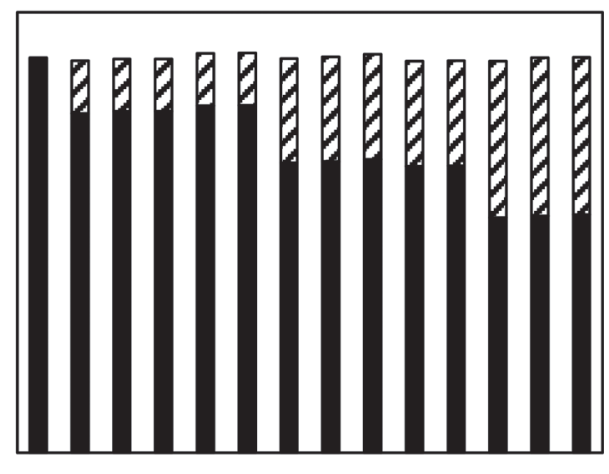

d)

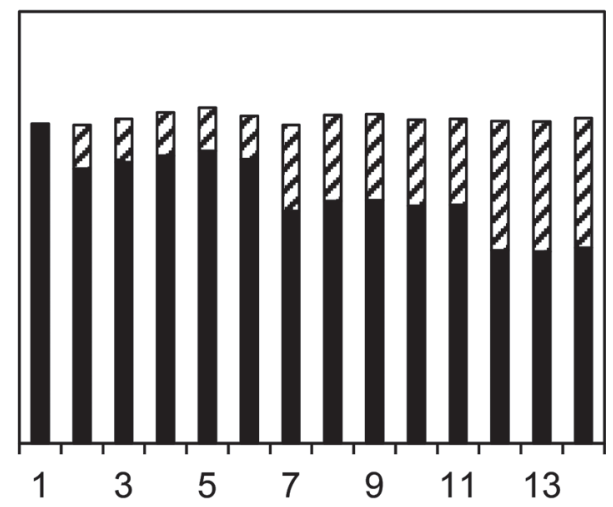

Measurement day

Figure 1. Mean DMI for each of the treatment groups. (a) ALF6 = cows fed alfalfa hay with wheat introduced over 6 d; (b) ALF11 = cows fed alfalfa hay with wheat introduced over $11 \mathrm{~d}$; (c) PRG6 = cows fed perennial ryegrass hay with wheat introduced over 6 d; (d) PRG11 = cows fed perennial ryegrass hay with wheat introduced over $11 \mathrm{~d}$. Intake of individual feed components is represented as solid black bars for forage and lined bars for wheat. 
6- and 11-d strategies. The rate at which ruminal fluid $\mathrm{pH}$ declined following feeding was affected by the type of forage being consumed. On average, the ruminal fluid $\mathrm{pH}$ of cows consuming alfalfa hay declined by 0.14 $\mathrm{pH}$ units/h, whereas that of cows consuming PRG hay declined by $0.07 \mathrm{pH}$ units/h. The difference between the forages was significant at all levels of wheat inclusion. We noted a greater rate of decline when wheat comprised $40 \%$ of the diet compared with all other wheat proportions. We found no differences in rates of $\mathrm{pH}$ decline between 0,13 , and $27 \%$ wheat. The average change in mean, minimum, and maximum ruminal fluid $\mathrm{pH}$, relative to the previous day, for every additional kilogram of wheat consumed is presented in Table 4. All $\mathrm{pH}$ parameters declined when wheat was added to the diet, irrespective of treatment. However, we observed a difference between forages. Feeding alfalfa hay resulted in a greater decrease in mean $(-0.05$ vs. -0.02$)$, minimum ( -0.07 vs. -0.03$)$, and maximum $\mathrm{pH}(-0.04$ vs. -0.01 ) with every additional kilogram of DM of wheat. We noted a forage by adaptation strategy interaction for minimum $\mathrm{pH}$. The decline in minimum $\mathrm{pH}$ with every additional kilogram DM of wheat was not different for the 2 alfalfa hay treatments, but PRG11 showed a greater decline than PRG6. The daily maximum, mean, and minimum ruminal fluid $\mathrm{pH}$ averages for each treatment are shown in Figure 4. Of note are the significantly lower values in mean and minimum $\mathrm{pH}$ for ALF6 cows compared with all other treatments on d 8, 9, and $10(P<0.001)$. On these days, ALF6 cows had daily minimum $\mathrm{pH}$ values below 6.00 , including the lowest $\mathrm{pH}$ reached for any of the treatments (5.72 on $d 9$ ). None of the other treatments resulted in any ruminal fluid $\mathrm{pH}$ values below 6.00 .

We observed a strong negative correlation between ruminal fluid $\mathrm{pH}$ and VFA concentrations $(r=-0.95)$. Total VFA concentrations were higher in the ruminal fluid of cows consuming alfalfa hay than in those consuming PRG hay (Table 3). For all treatments, the total concentration of VFA increased after feeding but the increase was much greater for cows fed alfalfa hay. The lipogenic-to-glucogenic VFA ratio [(acetate + butyrate)/propionate] decreased as more wheat was included in the diet and also with feeding. Sampling time affected the proportion of propionate, with an increase occurring postfeed, a difference that was more pronounced in cows fed alfalfa hay. Sampling time also affected the proportion of butyrate for cows fed alfalfa hay, with a lower proportion in the postfeed sample. For both forage treatments, acetate proportion declined as the amount of wheat in the diet increased. For cows fed PRG hay, the acetate proportion also decreased after feeding, a difference that was not observed in al- falfa hay-fed cows. The proportion of valerate increased postfeed and the difference was much greater in PRG hay-fed cows. Ammonia concentrations were greater in cows fed alfalfa hay than those fed PRG hay. For both forages, the concentration declined as the proportion of wheat in the diet increased. The concentration of Dlactate increased postfeed in the ruminal fluid of cows consuming alfalfa hay. We observed no difference between the pre- and postfeed concentrations of D-lactate in the rumen fluid of cows consuming PRG hay, but we noted a trend in the same direction. L-Lactate concentrations increased postfeed irrespective of forage type. Both D- and L-lactate concentrations increased for all treatments with increasing proportions of wheat.

\section{Milk Yield and Composition}

Mean daily MY and ECM yield, as well as the proportions of protein, fat, and lactose (averaged over the measurement period) are presented in Table 5. Cows fed alfalfa hay had higher yields than cows fed PRG hay. We observed an interaction between forage type and adaptation strategy for both MY and ECM yield.

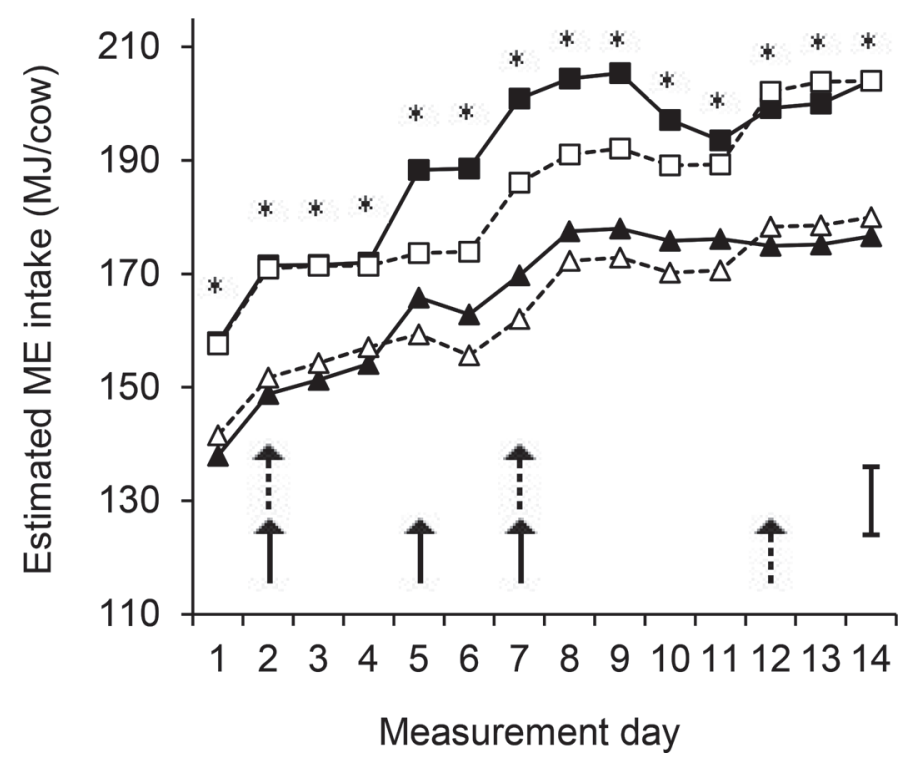

Figure 2. Daily estimated ME intakes of cows fed via each of the treatments. ALF6 (solid squares) = cows fed alfalfa hay and introduced wheat over $6 \mathrm{~d}$; ALF11 (empty squares) = cows fed alfalfa hay with wheat introduced over $11 \mathrm{~d}$; PRG6 (solid triangles) = cows fed perennial ryegrass hay with wheat introduced over 6 d; PRG11 (empty triangles) $=$ cows fed perennial ryegrass hay and introduced wheat over $11 \mathrm{~d}$. Values presented are means. The solid arrows indicate days an increase in wheat occurred for ALF6 and PRG6. Dotted arrows indicate days an increase in wheat occurred for ALF11 and PRG11. An asterisk indicates days when means differ $(P<0.05)$ and the error bar is the least significant difference for comparing treatments within each day. 
RUSSO ET AL.

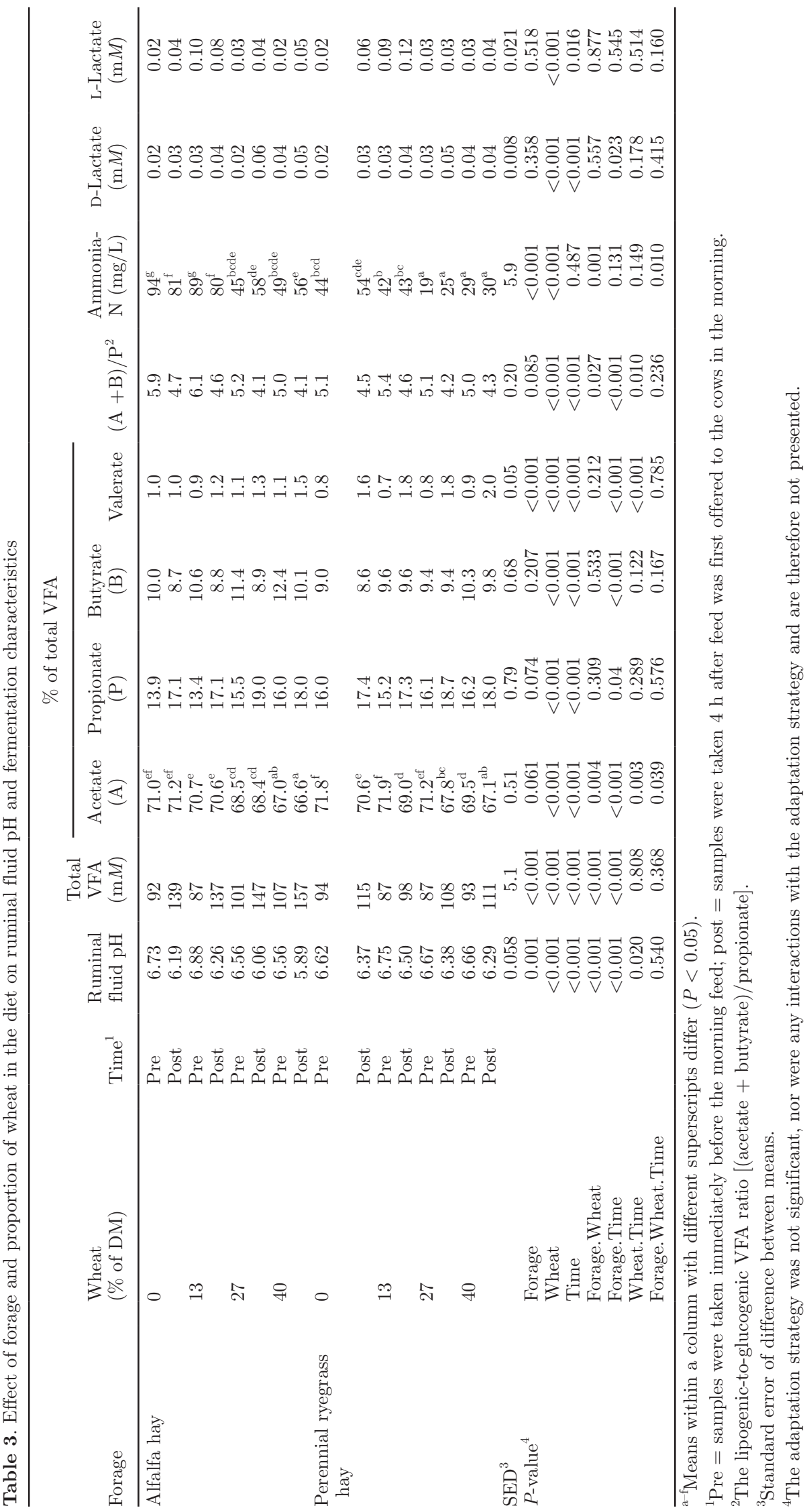




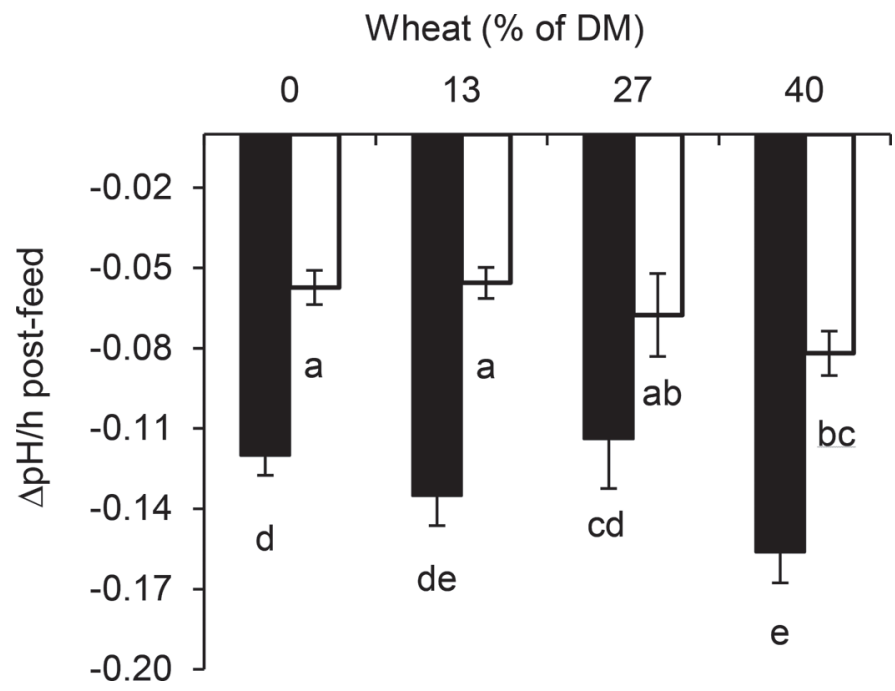

Figure 3. Change in ruminal fluid $\mathrm{pH} / \mathrm{h}$ during the $4 \mathrm{~h}$ after the morning feed commenced, when cows from each treatment group were fed on each of the 4 wheat proportions. Data were averaged across the 2 adaptation strategies. The 2 types of forages are represented as black bars for alfalfa hay and white bars for perennial ryegrass hay. Values presented are means. Error bars indicate SEM. Means with different letters $(\mathrm{a}-\mathrm{e})$ differ $(P<0.05)$.

When alfalfa hay was fed the 6-d adaptation strategy resulted in greater yields, but we found no differences between the adaptation strategies when PRG hay was fed. The cows fed PRG hay had a greater concentration of protein in their milk. We noted an interaction between the effects of adaptation strategy and forage type resulting in a greater concentration of lactose in the milk from PRG6 cows compared with PRG11 cows, but we observed no difference between the 2 alfalfa hay treatments. The ECM yields for both of the alfalfa hay treatments increased $(P<0.001)$ throughout the measurement period (daily data not shown). Despite the overall difference in mean ECM yield, both alfalfa hay treatments had equal yields on d $1(17.6 \mathrm{~kg} / \mathrm{cow}$ per day) and equal yields again by d $14(18.7 \mathrm{~kg} /$ cow per day). On d 5 through 9 , cows in the ALF 6 treatment were producing greater quantities of ECM than cows in the ALF11 treatment group, with the difference ranging from 1.6 to $2.9 \mathrm{~kg} /$ cow per day.

\section{Eating Behavior}

Eating behavior data are presented in Table 6. Forage type had a small effect on the amount of time per day cows spent eating. Cows consuming alfalfa hay spent more time eating than those fed PRG hay (208 and 189 $\mathrm{min}$ /cow per day, respectively). The amount of time spent ruminating and the amount of time spent not chewing were not different between the forage types. All behaviors were affected by the proportion of wheat in the diet. Cows spent less time eating and ruminating when wheat made up $40 \%$ of DM compared with an all-forage diet, which translated to more time spent not chewing.

\section{Forage Buffering Capacity}

The results of the acid titrations for both of the forages are presented in Table 7 . The titratable acidity of the 2 forages differed. Due to a higher initial $\mathrm{pH}$, almost twice as much acid was required to reduce the $\mathrm{pH}$ of PRG hay from initial $\mathrm{pH}$ to 5.50 compared with alfalfa hay. The buffering capacity, which describes the amount of acid required to produce a unit change in $\mathrm{pH}$ regardless of the initial $\mathrm{pH}$, was twice as much for alfalfa hay.

\section{DISCUSSION}

We found marked differences in ruminal $\mathrm{pH}$ parameters between the 2 forage types. Both forages provided good buffering within the rumen, but, contrary to our

Table 4. Effect of additional wheat on ruminal fluid mean, minimum, and maximum $\mathrm{pH}$

\begin{tabular}{|c|c|c|c|c|c|c|c|c|}
\hline \multirow[b]{2}{*}{ Item } & \multicolumn{4}{|c|}{ Treatment $^{1}$} & \multirow[b]{2}{*}{$\mathrm{SED}^{3}$} & \multicolumn{3}{|c|}{$P$-value } \\
\hline & ALF6 & ALF11 & PRG6 & PRG11 & & Forage & $\begin{array}{l}\text { Adaptation } \\
\text { strategy }\end{array}$ & Interaction \\
\hline
\end{tabular}


first hypothesis, cows consuming alfalfa hay had a greater decline in ruminal $\mathrm{pH}$ after eating and a lower daily mean $\mathrm{pH}$. A main driver of this was likely the higher DMI of cows consuming alfalfa hay compared with cows offered PRG hay. The voluntary intake of grasses is typically less than that of legumes due to greater NDF fractions contributing to a slower rate of passage and increased ruminal fill (Thornton and Minson, 1973; Dado and Allen, 1995). The higher intake of cows fed alfalfa hay would have meant more microbial fermentation of feed within the rumen, resulting in a greater production of VFA, and lower ruminal $\mathrm{pH}$ (Krause and Oetzel, 2006). In support of this, total VFA concentrations were consistently higher in cows fed alfalfa hay, with a greater quantity produced after feeding.

The higher DMI would also explain the more rapid decline in $\mathrm{pH}$ after eating, as rate of ruminal $\mathrm{pH}$ decline increases with meal size (Allen, 1997). Additionally, as saliva is the main contributor to buffering within the rumen (Bailey and Balch, 1961), the eating behavior of the treatment groups needs to be considered. We observed no differences in time spent ruminating between cows on the 2 forages, but cows fed alfalfa hay spent an extra 19 min eating per day. As saliva flow is greater during eating compared with resting (Cassida and Stokes, 1986), this would lead to the assumption that cows fed alfalfa hay had a greater influx of saliva into the rumen each day. However, as their ruminal $\mathrm{pH}$ was lower overall and declined further after eating, it would appear that the buffering benefits from the additional saliva were not enough to overcome the greater reduction in $\mathrm{pH}$ due to feed fermentation. Cows offered alfalfa hay had a maximum wheat intake of 7.4 $\mathrm{kg}$ of $\mathrm{DM} / \mathrm{cow}$ per day, whereas cows fed PRG hay had a maximum wheat intake of $6.3 \mathrm{~kg}$ of $\mathrm{DM} /$ cow per day. The differences in wheat intake could have influenced ruminal $\mathrm{pH}$, and so $\mathrm{pH}$ was expressed as change in $\mathrm{pH}$ per kilogram of extra wheat consumed to account for the variability. The mean, maximum, and minimum ruminal $\mathrm{pH}$ (relative to the day before) declined with every extra kilogram of wheat consumed, irrespective of forage type. However, the drop in each of the parameters was at least twice as much for the alfalfa hay treatments. Despite the fact that grasses are typically of higher digestibility, legumes have a larger rapidly digested fraction (Thornton and Minson, 1973; Schofield and Pell, 1995) breaking down quicker within the rumen (Van Soest, 1994), perhaps explaining the greater decline in $\mathrm{pH}$ seen immediately after eating within the current experiment.

The greater concentration of lactic acid postfeed for the alfalfa treatments would have also played a role in reducing ruminal $\mathrm{pH}$, as lactic acid is particularly
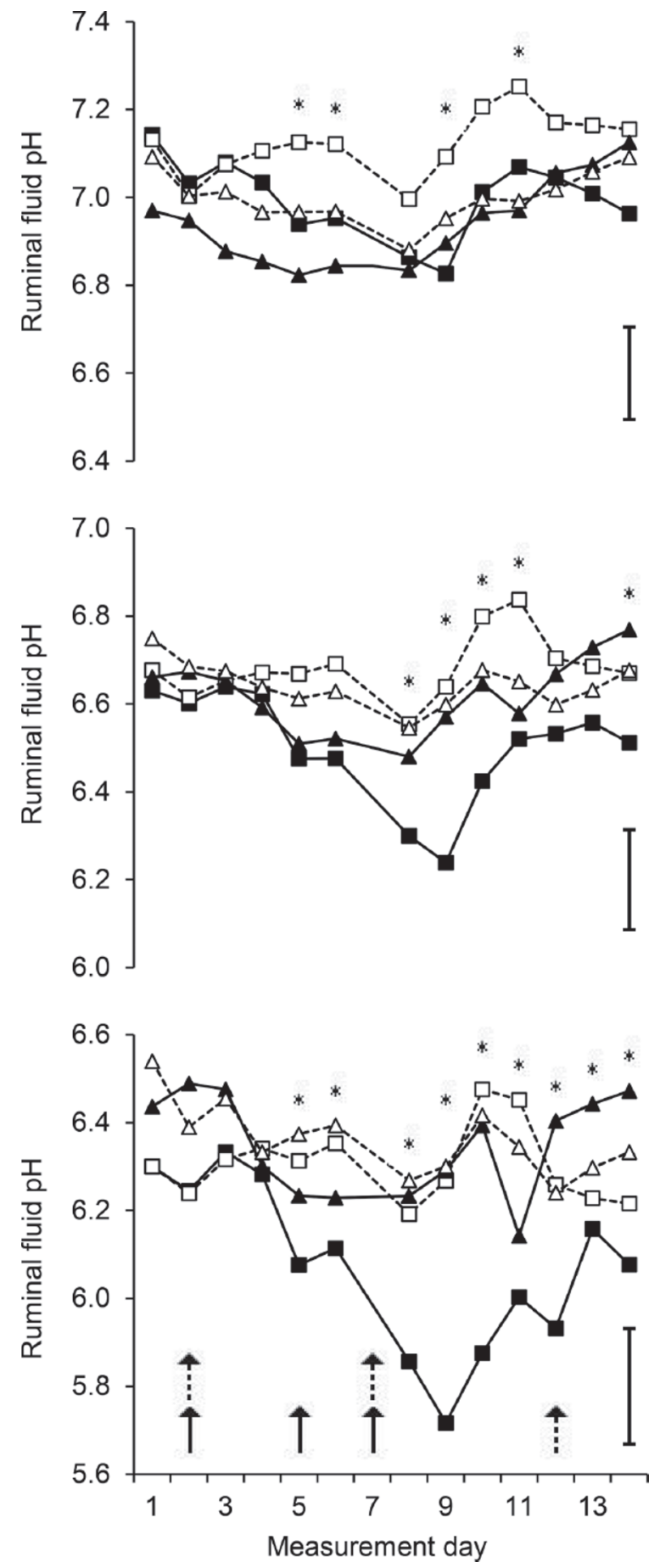

Figure 4. The daily (a) maximum, (b) mean, and (c) minimum ruminal fluid $\mathrm{pH}$ of cows fed via each of the different treatments. ALF6 (solid squares) = cows fed alfalfa hay with wheat introduced over $6 \mathrm{~d}$; ALF11 (empty squares) = cows fed alfalfa hay with wheat introduced over $11 \mathrm{~d}$; PRG6 (solid triangles) = cows fed perennial ryegrass hay with wheat introduced over $6 \mathrm{~d}$; PRG11 (empty triangles) = cows fed perennial ryegrass hay with wheat introduced over $11 \mathrm{~d}$. Values presented are means. The solid arrows indicate days an increase in wheat occurred for ALF6 and PRG6. Dotted arrows indicate days an increase in wheat occurred for ALF11 and PRG11. An asterisk indicates days when means differ $(P<0.05)$ and the error bar is the least significant difference for comparing treatments within each day. 
Table 5. Mean daily milk yield (MY), ECM yield, and composition of milk from cows fed according to each of the treatments

\begin{tabular}{|c|c|c|c|c|c|c|c|c|}
\hline \multirow[b]{2}{*}{ Item } & \multicolumn{4}{|c|}{ Treatment $^{1}$} & \multirow[b]{2}{*}{$\mathrm{SED}^{2}$} & \multicolumn{3}{|c|}{$P$-value } \\
\hline & ALF6 & ALF11 & PRG6 & PRG11 & & Forage & $\begin{array}{c}\text { Adaptation } \\
\text { strategy }\end{array}$ & Interaction \\
\hline ECM (kg/cow per day) & $19.5^{\mathrm{a}}$ & $18.0^{\mathrm{b}}$ & $14.8^{\mathrm{c}}$ & $15.0^{\mathrm{c}}$ & 0.37 & $<0.001$ & 0.019 & 0.002 \\
\hline Protein (\%) & 3.66 & 3.65 & 3.74 & 3.67 & 0.03 & 0.020 & 0.051 & 0.123 \\
\hline Fat $(\%)$ & 4.66 & 4.63 & 4.73 & 4.67 & 0.09 & 0.406 & 0.510 & 0.853 \\
\hline
\end{tabular}

${ }^{\mathrm{a}-c}$ Means within a row with different superscripts differ $(P<0.05)$.

${ }^{1}$ Treatments: ALF6 = cows fed alfalfa hay with wheat introduced over $6 \mathrm{~d}$; ALF11 = cows fed alfalfa hay with wheat introduced over $11 \mathrm{~d}$; PRG6 $=$ cows fed perennial ryegrass hay with wheat introduced over $6 \mathrm{~d}$; PRG11 = cows fed perennial ryegrass hay with wheat introduced over $11 \mathrm{~d}$.

${ }^{2}$ Standard error of difference between treatments.

influential in depressing ruminal $\mathrm{pH}$ (Dijkstra et al., 2012). Lactic acid accumulation is typical during dietary adaptation, particularly with the introduction of readily fermentable carbohydrates (France, 1975; Counotte and Prins, 1981), and so the increase in ruminal concentrations of D- and L-lactate with the introduction of wheat is not surprising. Despite the increase of lactic acid, it did not accumulate to a level symptomatic of lactic acidosis, reported to be above $40 \mathrm{~m} M$ in severe cases (Owens et al., 1998).

The acid buffering capacity of alfalfa hay was almost double that of PRG hay, yet this did not result in a greater $\mathrm{pH}$ stability within the rumen. Previous work has described the high intrinsic buffering capacity of alfalfa hay compared with the majority of other ruminant feeds (Crawford et al., 1983). Despite the varied intrinsic buffering capacity of feeds, it has been reported to have little influence within the rumen, particularly compared with saliva and VFA (Counotte et al., 1979; Wohlt et al., 1987; Allen, 1997); however, few have test- ed this in vivo. The results of the titrations within the current experiment appear to further support this. It would appear the initial $\mathrm{pH}$ and the titratable acidity, rather than the buffering capacity, is a better predictor of effects within ruminal fluid. The higher initial $\mathrm{pH}$ of PRG hay meant more acid was required to reduce the $\mathrm{pH}$ to 5.50 , resulting in a greater titratable acidity at $\mathrm{pH}$ levels relative to normal rumen function, indicating PRG hay as better forage for rapid grain introduction.

The DCAD of the diets within the current experiment ranged from 25 to $62 \mathrm{mEq} / 100 \mathrm{~g}$ of $\mathrm{DM}$ and were mostly within an optimum range for lactating dairy cows, 25 to $50 \mathrm{mEq} / 100 \mathrm{~g}$ of DM (Sanchez et al., 1994). In vitro acid buffering capacity correlates strongly with the total cation fraction of feeds (Jasaitis et al., 1987). Diets with a greater DCAD have been associated with higher ruminal fluid $\mathrm{pH}$ and increased DMI (Tucker et al., 1988; Wildman et al., 2007). The alfalfa hay diets had a higher DCAD, yet this did not translate to a greater ability to buffer the ruminal contents. Another

Table 6. Eating behavior data as observed for $24 \mathrm{~h}$ on d 1 and d 14 when wheat made up 0 and $40 \%$ of the diet, respectively

\begin{tabular}{|c|c|c|c|c|}
\hline Treatment $^{1}$ & Wheat ( $\%$ of DM) & $\begin{array}{c}\text { Eating } \\
(\mathrm{min} / \text { cow per day })\end{array}$ & $\begin{array}{c}\text { Ruminating } \\
\text { (min/cow per day) }\end{array}$ & $\begin{array}{c}\text { Not chewing } \\
\text { (min/cow per day) }\end{array}$ \\
\hline \multirow[t]{2}{*}{ ALF6 } & 0 & 274 & 460 & 706 \\
\hline & 40 & 136 & 385 & 919 \\
\hline ALF11 & 40 & 126 & 325 & 989 \\
\hline \multirow[t]{2}{*}{ PRG6 } & 0 & 283 & 506 & 651 \\
\hline & 40 & 104 & 383 & 953 \\
\hline \multirow[t]{3}{*}{$P$-value ${ }^{3}$} & Forage & 0.039 & 0.325 & 0.896 \\
\hline & Adaptation strategy & 0.809 & 0.069 & 0.250 \\
\hline & Wheat & $<0.001$ & $<0.001$ & $<0.001$ \\
\hline
\end{tabular}

${ }^{1}$ Treatments: ALF6 = cows fed alfalfa hay with wheat introduced over $6 \mathrm{~d}$; ALF11 = cows fed alfalfa hay with wheat introduced over 11 d; PRG6 $=$ cows fed perennial ryegrass hay with wheat introduced over $6 \mathrm{~d}$; PRG11 = cows fed perennial ryegrass hay with wheat introduced over $11 \mathrm{~d}$. ${ }^{2}$ Standard error of difference between treatments.

${ }^{3}$ No interactions were significant so are not presented. 
Table 7 . Results of the acid titrations conducted on alfalfa hay and perennial ryegrass (PRG) hay from initial $\mathrm{pH}$ to $\mathrm{pH} 5.50$

\begin{tabular}{|c|c|c|c|c|}
\hline Item & $\begin{array}{c}\text { Alfalfa } \\
\text { hay }\end{array}$ & PRG hay & $\mathrm{SED}^{1}$ & $P$-value \\
\hline Initial pH & 5.77 & 6.50 & 0.07 & $<0.001$ \\
\hline 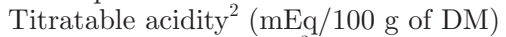 & 5.9 & 11.0 & 0.93 & 0.005 \\
\hline Acid buffering capacity & 22.0 & 11.0 & 0.12 & $<0.001$ \\
\hline
\end{tabular}

driver of buffering capacity might be CP concentration, as ammonia is the main alkali within the rumen (Crawford et al., 1983) and ruminal fluid ammonia concentrations are typically a reflection of the $\mathrm{CP}$ concentration of a diet (Elizalde et al., 1996). The higher CP concentration of alfalfa hay explains the higher ammonia concentrations in the ruminal fluid of cows consuming it within the current experiment. However, contrary to what we expected, the greater $\mathrm{CP}$ concentration and subsequent rumen ammonia concentrations from alfalfa hay did not result in increased ruminal $\mathrm{pH}$ relative to PRG hay. This suggests the increase in VFA production, driven by the higher DMI, outweighed the possible $\mathrm{pH}$ benefits of the increased ammonia concentrations.

Our second hypothesis, that the mean ruminal fluid $\mathrm{pH}$ of cows would not differ between the 2 wheat adaptation strategies, irrespective of forage type, was not supported. Large differences were observed between the daily mean and minimum ruminal $\mathrm{pH}$ values of the 2 alfalfa hay treatments (see Figure 4). The differences in the daily $\mathrm{pH}$ values appeared to be driven by the rapid increase of wheat over $6 \mathrm{~d}$ versus the more gradual increase over $11 \mathrm{~d}$. As the 6 -d adaptation strategy was rapidly increasing the ME content of the diet, it did not allow for the ruminal $\mathrm{pH}$ of cows to recover, resulting in a declining ruminal $\mathrm{pH}$. Despite the mean daily $\mathrm{pH}$ falling to levels considered low (<6.0; Pitt et al., 1996), cows on the ALF6 treatment produced $1.5 \mathrm{~kg} /$ cow per day more ECM over $14 \mathrm{~d}$ than cows on the ALF11 treatment. This difference was driven by higher yields on d 5 through 9, when ALF6 cows were consuming $\sim 14 \mathrm{MJ} /$ cow per day more than ALF11 cows. This also corresponds with some of the days ALF6 cows were generating their lowest ruminal $\mathrm{pH}$ values.

No difference in ECM yields was observed between the adaptation strategies, when cows were fed PRG hay. This is likely due to the higher estimated ME concentration and lower intake of the PRG hay, which resulted in similar estimated ME intakes from the $2 \mathrm{PRG}$ hay treatment groups. Substituting wheat for alfalfa hay caused larger variation to estimated ME intake compared with the same proportional substitution for
PRG hay (see Figure 2). Despite the lower estimated ME proportion of the forage, cows consuming alfalfa hay had a greater estimated ME intake overall, as they were eating $3.1 \mathrm{~kg}$ of $\mathrm{DM} /$ cow per day more. This difference in DMI, and subsequently estimated ME intake, resulted in a greater MY from the alfalfa hay-fed cows. The combination of the 6-d adaptation strategy paired with a reduced buffering ability and the lower estimated ME concentration of the alfalfa hay resulted in only the cows in the ALF6 treatment exhibiting daily mean ruminal $\mathrm{pH}$ values below 6.00. Despite the $\mathrm{pH}$ reaching levels considered to compromise digestion, no other measured parameter suggested poor adaptation or acidosis. In fact, it was these cows, with the lowest ruminal $\mathrm{pH}$ values that had the highest MY. This relationship is consistent with that observed by Kolver and De Veth (2002), who reported that the performance of pasture-fed dairy cows was not adversely affected by a mean ruminal $\mathrm{pH}$ of 5.80 to 6.20 .

\section{CONCLUSIONS}

Milk yield and rumen responses to the wheat adaptation strategies varied depending on the base forage. Both forages demonstrated good buffering within the rumen and sufficiently stimulated rumination and associated saliva secretion, allowing cows to cope with the rapid starch load of the 6-d adaptation strategy. However, the greater intake of the alfalfa hay and its lower estimated ME concentration meant cows on the ALF6 treatment benefited substantially from the rapid input of wheat and increase in dietary ME. This resulted in cows on the 6-d strategy producing more milk than those on the 11-d adaptation strategy, whose increase in dietary estimated ME was more gradual. We found no differences between the 6- and 11-d adaptation strategies when PRG hay was fed. These results indicate that some subtle changes to grain introduction methods can lead to increased MY, depending on intake and forage choice. Feeding alfalfa hay produced lower ruminal fluid $\mathrm{pH}$, possibly driven by a greater intake and increased fermentation within the rumen. Despite 
the rapid introduction of large amounts of wheat and some differences seen between the forages, none of the treatment groups indicated compromised production, with neither adaptation strategy posing any significant threats to biological function. Both forages buffered the rumen against potentially detrimental $\mathrm{pH}$ changes often seen with the introduction of large amounts of rapidly fermentable starch, highlighting the important role forages play when adapting dairy cows to large amounts of concentrates.

\section{ACKNOWLEDGMENTS}

The authors are grateful to G. Morris, A. McDonald, A. Hookey, D. Wilson, M. Douglas, L. Marett, M. Wright, C. Lewis, D. Mapleson, M. Jenkin, D. Stayches, L. Dorling, B. Ribaux, K. Rabl, R. Williams, and P. Moate (Agriculture Victoria Research, Ellinbank, Australia) for all their help, day and night. This research was funded by Agriculture Victoria Research, Dairy Australia, Teagasc (Ireland), and The University of Melbourne.

\section{REFERENCES}

Allen, M. S. 1997. Relationship between fermentation acid production in the rumen and the requirement for physically effective fiber. J. Dairy Sci. 80:1447-1462.

Allen, M. S., J. A. Voelker, and M. Oba. 2006. Physically effective fiber and regulation of ruminal $\mathrm{pH}$ : More than just chewing. Pages 270-278 in Production Diseases in Farm Animals. N. P. Joshi and T. H. Herdt, ed. Wageningen Academic Publishers, Wageningen, the Netherlands.

Auldist, M. J., L. C. Marett, J. S. Greenwood, M. C. Hannah, J. L. Jacobs, and W. J. Wales. 2013. Effects of different strategies for feeding supplements on milk production responses in cows grazing a restricted pasture allowance. J. Dairy Sci. 96:1218-1231.

Bailey, C. B., and C. C. Balch. 1961. Saliva secretion and its relation to feeding in cattle. 2. The composition and rate of secretion of mixed saliva in the cow during rest. Br. J. Nutr. 15:383-402.

Bargo, F., L. D. Muller, E. S. Kolver, and J. E. Delahoy. 2003. Invited review: Production and digestion of supplemented dairy cows on pasture. J. Dairy Sci. 86:1-42.

Cassida, K. A., and M. R. Stokes. 1986. Eating and resting salivation in early lactation dairy cows. J. Dairy Sci. 69:1282-1292.

Counotte, G. H. M., and R. A. Prins. 1981. Regulation of lactate metabolism in the rumen. Vet. Res. Commun. 5:101-115.

Counotte, G. H. M., A. T. van't Klooster, J. van der Kuilen, and R. A. Prins. 1979. An analysis of the buffer system in the rumen of dairy cattle. J. Anim. Sci. 49:1536-1544.

Crawford, R. J., B. J. Shriver, G. A. Varga, and W. H. Hoover. 1983. Buffer requirements for maintenance of $\mathrm{pH}$ during fermentation of individual feeds in continuous cultures. J. Dairy Sci. 66:1881-1890.

Dado, R. G., and M. S. Allen. 1995. Intake limitations, feeding behavior, and rumen function of cows challenged with rumen fill from dietary fiber or inert bulk. J. Dairy Sci. 78:118-133.

Dairy Australia. 2015. Dairy Feeding Update. Dairy Australia, Melbourne.

Dijkstra, J., J. L. Ellis, E. Kebreab, A. B. Strathe, S. López, J. France, and A. Bannink. 2012. Ruminal pH regulation and nutritional consequences of low pH. Anim. Feed Sci. Technol. 172:22-33.

Elizalde, J. C., F. J. Santini, and A. M. Pasinato. 1996. The effect of stage of harvest on the processes of digestion in cattle fed winter oats indoors. II. Nitrogen digestion and microbial protein synthesis. Anim. Feed Sci. Technol. 47:245-255.

France, R. T. 1975. The use of dehydrated grass in rations for early weaned lambs and some physiological effects of a rapid ration changeover. PhD thesis, University of British Columbia, Vancouver, Canada.

Gary, L. A., G. W. Sherritt, and E. B. Hale. 1970. Behavior of Charolais cattle on pasture. J. Anim. Sci. 30:203-206.

Gonzalez-Rivas, P. A., K. DiGiacomo, V. M. Russo, B. J. Leury, J. J. Cottrell, and F. R. Dunshea. 2016. Feeding slowly fermentable grains has the potential to ameliorate heat stress in grain-fed wethers. J. Anim. Sci. 94:2981-2991.

Greenhill, W. L. 1964. The buffering capacity of pasture plants with special reference to ensilage. Crop Pasture Sci. 15:511-519.

Harville, D. A. 1974. Nearly optimal allocation of experimental units using observed covariate values. Technometrics 16:589-599.

Hutjens, M. F., and T. R. Overton. 1996. Monitoring milk production: optimizing rumen digestion in the dairy cow. Pages 203-221 in Herd Health and Production Management in Dairy Practice. A. Brand, J. P. T. M. Noordhuizen, and K. Schirmann, ed. Wageningen Press, Wageningen, the Netherlands.

Jasaitis, D. K., J. E. Wohlt, and J. L. Evans. 1987. Influence of feed ion content on buffering capacity of ruminant feedstuffs in vitro. J Dairy Sci. 70:1391-1403.

Kaufmann, W. 1976. Influence of the composition of the ration and the feeding frequency on ph-regulation in the rumen and on feed in-take in ruminants. Livest. Prod. Sci. 3:103-114.

Kellaway, R., and T. Harrington. 2004. Feeding Concentrates: Supplements for Dairy Cows. Landlinks Press, Melbourne, Australia.

Kolver, E. S., and M. J. De Veth. 2002. Prediction of ruminal pH from pasture-based diets. J. Dairy Sci. 85:1255-1266.

Krause, K. M., and G. R. Oetzel. 2006. Understanding and preventing subacute ruminal acidosis in dairy herds: A review. Anim. Feed Sci. Technol. 126:215-236.

Leaver, J. D. 1988. Level and pattern of concentrate allocation to dairy cows. Pages 315-326 in Nutrition and Lactation in the Dairy Cow. P. C. Garnsworthy, ed. Butterworths, London, UK.

McBurney, M. I., P. J. Van Soest, and L. E. Chase. 1983. Cation exchange capacity and buffering capacity of neutral-detergent fibres. J. Sci. Food Agric. 34:910-916

Moate, P. J., S. R. O. Williams, J. L. Jacobs, M. C. Hannah, K. A. Beauchemin, R. J. Eckard, and W. J. Wales. 2017. Wheat is more potent than corn or barley for dietary mitigation of enteric methane emissions from dairy cows. J. Dairy Sci. 100:7139-7153.

Mould, F. L., E. R. Ørskov, and S. O. Mann. 1983. Associative effects of mixed feeds. I. Effects of type and level of supplementation and the influence of the rumen fluid $\mathrm{pH}$ on cellulolysis in vivo and dry matter digestion of various roughages. Anim. Feed Sci. Technol. $10: 15-30$.

National Health and Medical Research Council. 2013. Australian Code of Practice for the Care and Use of Animals for Scientific Purposes. Australian Government, Canberra.

NRC. 2001. Nurient Requirements of Dairy Cattle. 7th Rev. ed. Natl. Acad. Press, Washington, DC.

Owens, F. N., D. S. Secrist, W. J. Hill, and D. R. Gill. 1998. Acidosis in cattle: A review. J. Anim. Sci. 76:275-286.

Packer, E. L., E. H. Clayton, and P. M. V. Cusack. 2011. Rumen fermentation and liveweight gain in beef cattle treated with monensin and grazing lush forage. Aust. Vet. J. 89:338-345.

Pitt, R. E., J. S. Van Kessel, D. G. Fox, A. N. Pell, M. C. Barry, and P. J. Van Soest. 1996. Prediction of ruminal volatile fatty acids and $\mathrm{pH}$ within the net carbohydrate and protein system. J. Anim. Sci. 74:226-244.

Playne, M. J., and P. McDonald. 1966. The buffering constituents of herbage and of silage. J. Sci. Food Agric. 17:264-268.

QuikChem Systems. 2008. Quickchem method no. 12.107-06-I-A. QuikChem Systems, Division of Lachat Chemicals Inc., Loveland, CO.

Roche, J. R., L. R. Turner, J. M. Lee, D. C. Edmeades, D. J. Donaghy, K. A. Macdonald, J. W. Penno, and D. P. Berry. 2009. Weather, herbage quality and milk production in pastoral systems. 2. Tem- 
poral patterns and intra-relationships in herbage quality and mineral concentration parameters. Anim. Prod. Sci. 49:200-210.

Sanchez, W. K., D. K. Beede, and M. A. Delorenzo. 1994. Macromineral element interrelationships and lactational performance: Empirical models from a large data set. J. Dairy Sci. 77:3096-3110.

Schofield, P., and A. N. Pell. 1995. Measurement and kinetic analysis of the neutral detergent-soluble carbohydrate fraction of legumes and grasses. J. Anim. Sci. 73:3455-3463.

Smith, L. W., H. K. Goering, and C. H. Gordon. 1972. Relationships of forage compositions with rates of cell wall digestion and indigestibility of cell walls. J. Dairy Sci. 55:1140-1147.

Thornton, R. F., and D. J. Minson. 1973. The relationship between apparent retention time in the rumen, voluntary intake, and apparent digestibility of legume and grass diets in sheep. Aust. J. Agric. Res. 24:889-898.

Tremere, A. W., W. G. Merrill, and J. K. Loosli. 1968. Adaptation to high concentrate feeding as related to acidosis and digestive disturbances in dairy heifers. J. Dairy Sci. 51:1065-1072.

Tucker, W. B., G. A. Harrison, and R. W. Hemken. 1988. Influence of dietary cation-anion balance on milk, blood, urine, and rumen fluid in lactating dairy cattle. J. Dairy Sci. 71:346-354.
Tyrrell, H. F., and J. T. Reid. 1965. Prediction of the energy value of cow's milk. J. Dairy Sci. 48:1215-1223.

Van Soest, P. J. 1965. Symposium on factors influencing the voluntary intake of herbage by ruminants: voluntary intake in relation to chemical composition and digestibility. J. Anim. Sci. 24:834-843.

Van Soest, P. J. 1994. Nutritional Ecology of the Ruminant. Cornell University Press, Ithaca, NY.

Wales, W. J., and P. T. Doyle. 2003. Effect of grain and straw supplementation on marginal milk-production responses and rumen fermentation of cows grazing highly digestible subterranean clover pasture. Anim. Prod. Sci. 43:467-474.

Warner, A. C. I. 1962. Some factors influencing the rumen microbial population. J. Gen. Microbiol. 28:129-146.

Wildman, C. D., J. W. West, and J. K. Bernard. 2007. Effect of dietary cation-anion difference and dietary crude protein on milk yield, acid-base chemistry, and rumen fermentation. J. Dairy Sci. 90:4693-4700.

Wohlt, J. E., D. K. Jasaitis, and J. L. Evans. 1987. Use of acid and base titrations to evaluate the buffering capacity of ruminant feedstuffs in vitro. J. Dairy Sci. 70:1465-1470. 